\title{
An analysis of blood specimen container leakage
}

\author{
S. M. LEWIS AND J. M. WARDLE
}

From the Royal Postgraduate Medical School, Du Cane Road, London W12 0HS, UK

SUMMARY Procedures have been designed to test specimen containers for leakage, using blood and aqueous fluorescein solution as indicators. They have been used in a trial evaluation of a number of commercially available containers intended for medical specimens. Glass bijou bottles, evacuated container systems, and several types of plastic container showed no significant leakage rate with either blood or aqueous solution when they were tested at room temperature, but a large proportion of the plastic containers leaked after being subjected to $-20^{\circ} \mathrm{C}$. These would thus be suitable and satisfactory for blood count specimens but not for specimens of serum and other body fluids, which are usually stored frozen. With all types of container tested there was spontaneous discharge of contents (blood or aqueous solution) on opening in a proportion of them; thus no container at present available seems to be entirely free from hazard.

Leaking blood specimen containers (or tubes) cause (a) potential hazard of contamination of fingers by infected material, $(b)$ similar hazard of infection (as well as aesthetic displeasure) when blood contaminates the accompanying request form, and $(c)$ errors in measurement if the sample that is lost by leakage is not homogeneous with the specimen as a whole. The problem appears to be due essentially to design defects but also, in the case of plastic containers, to the materials used in their manufacture. In 1972, the British Standards Institution (BSI) prepared specifications for Medical Specimen Containers for Haematology and Biochemistry aimed at overcoming these defects. In parallel, the International Standards Organisation $(1977 \mathrm{a}, \mathrm{b})$ has drafted an international standard for Medical Specimen Containers up to $25 \mathrm{ml}$ Capacity, together with specifications for Evacuated Tubes for Blood Specimen Collection, and a similar document has been published by the US National Committee for Clinical Laboratory Standards (1977). These documents provide a description of the design and construction that should be complied with, and also include instructions for carrying out tests for leakage of stoppered containers and for spontaneous discharge of contents on opening a container, using a solution of fluorescein in $6 \%$ dextran as the indicator.

A number of manufacturers have made serious attempts to meet the BSI and ISO specifications, but leakage is still a problem; and a preliminary survey carried out under the aegis of the International

Received for publication 15 February 1978
Committee for Standardisation in Haematology has indicated that it is a world-wide one. Moreover, on many occasions, some of the specimens sent to the participants in the British National Haematology Proficiency Assessment Trials have leaked during their postal transit. In one study shortly after the publication of the British Standard, Cook (1972) showed that many types of containers then available failed the tests of leakage which were included in the BSI specifications. To some extent these tests might be considered to be contrived when assessing the containers for their blood-containing property as the fluorescein-dextran does not have the same rheological characteristics as blood. Accordingly for this present study, the leakage tests proposed by BSI have been modified, and other tests have been designed using whole blood as the indicator. This evaluation has been undertaken on behalf of the DHSS-BCSH National Quality Control Service. Batches of containers were obtained at random from 'off the shelf' supplies, and the evaluation was carried out on 50 or 100 tubes in a batch in accordance with the protocol described below. Both simple containers and evacuated container systems were tested, but restricted to those manufactured or marketed in Britain. It should be noted that some of the containers that were included in the trial have since been withdrawn or modified.

\section{Protocol of procedure}

SIMPLE CONTAINERS

Blood leakage

Four or $5 \mathrm{ml}$ of blood in EDTA, acid citrate dextrose 
(ACD), or heparin anticoagulant were added to each of 50 tubes, which were then capped with care by the normal routine procedure and transferred to a refrigerator at $4^{\circ} \mathrm{C}$ overnight. The next day the tubes were placed on a roller-type rotating mixer for $20 \mathrm{~min}$. They were then checked for leaks (preopening). Their caps were removed and carefully replaced, and they were again placed on the rotator for a further $20 \mathrm{~min}$, and then checked for leaks. This procedure was repeated once again. On each occasion the following faults were noted:

(a) Leakage out of the capped tube

(b) Bubbles of blood on outside between cap and tube or seepage down tube walls as cap was replaced (spray)

(c) Dried blood on outside of tube wall or on cap, visible when cap was removed.

The tests were rated on the basis of their practical importance taking account also of the number of times a tube could be opened and reclosed before it failed. Faults B and C were applicable to the tubes only after they had been opened. In all procedures, when a tube failed it was not tested further. But the scoring was based on the assumption that it would have failed on each subsequent test, and the score was appropriately biased, as follows:

\begin{tabular}{lllr} 
Fault & \multicolumn{3}{l}{ No. of times tube opened and reclosed } \\
\cline { 2 - 4 } & 0 & 1 & 2 \\
A & 40 & 20 & 10 \\
B & N/A & 10 & 5 \\
C & N/A & 10 & 5
\end{tabular}

The final rating was the accumulation of the units for each tube tested, expressed as a percentage of a maximum fail rate of 100 units per tube. As the test was designed to accord with standard practice in the routine laboratory, no special technique, such as the use of a torque wrench, was used to open and close the containers.

\section{Fluorescein test for aqueous fluid leakage}

Twenty-five grams of sodium fluorescein (uranine) were dissolved in $60 \mathrm{~g} / 1$ dextran 70 in 0.15 molar saline solution made up to one litre. Sufficient of the fluorescein solution was pipetted carefully into the bottom of each container to cover the capped section of the complete container when inverted. Care was taken not to contaminate the rims of the containers while pipetting.

The containers were capped securely. The inverted complete containers and contents were left for two hours at a temperature of $-20^{\circ} \mathrm{C}$. The complete containers were then immersed upside down individually in tubes of water and exposed for $2 \mathrm{~h}$ at $37^{\circ} \mathrm{C}$ and then immediately for a further $2 \mathrm{~h}$ at room temperature $\left(c 20^{\circ} \mathrm{C}\right)$. In some tests the contents of the tubes were not subjected to the initial freezing phase.

The containers were removed from the water, which was examined by ultraviolet light for traces of sodium fluorescein. Any evidence of fluorescein in the water indicated a defective tube, and results were recorded simply as a percentage of defective tubes in a batch.

Fluorescein test for spontaneous discharge of contents A volume of the sodium fluorescein solution was pipetted into each container, which was then closed by a routine procedure. The container was rotated on a roller type mixer for $5 \mathrm{~min}$, making sure that the sodium fluorescein solution was in contact with cap-container junction. The complete container was stood on its base for $2 \mathrm{~min}$ to allow it to drain. The cap was removed and replaced while the container was held approximately $150 \mathrm{~mm}$ above, and centrally over, a square sheet of dampened white absorbent paper at least $400 \times 400 \mathrm{~mm}$. During this operation the container was held in position for $15 \mathrm{~s}$ when the cap was replaced and held for a further $15 \mathrm{~s}$ before the paper was examined under ultraviolet light for traces of sodium fluorescein. Evidence of fluorescein was taken to indicate a defective tube.

\section{Spontaneous discharge of blood}

Twenty-five grams of fluorescein were added to one litre of blood in ACD. A volume was pipetted into each container, and the test for spontaneous discharge was performed as described above. The presence of blood specks or fluorescein on the paper, when examined in white light and ultraviolet light, respectively, was taken as evidence of spontaneous discharge from the container under test.

\section{EVACUATED CONTAINER SYSTEMS}

Fluorescein tests for aqueous fluid leakage

The same reagent was used as above. A reservoir of sodium fluorescein solution was attached to 1 metre plastic tubing fitted with a 20 gauge double-ended needle, or the needle provided for the system. Each of the containers was filled to its nominal capacity and removed from the needle. Any contamination on the outside of the closure was noted. The closure was washed in running tap water for 30 minutes with constant agitation and then wiped dry with a clean tissue.

The tubes were placed on a roller type mixer for $20 \mathrm{~min}$. The closures were inspected under ultraviolet light for any evidence of leakage. If none was present, the inverted containers and contents were left for $2 \mathrm{~h}$ at $-20^{\circ} \mathrm{C}$. The containers were then placed upside down in tubes of water and exposed 
for $2 \mathrm{~h}$ to a temperature of $37^{\circ} \mathrm{C}$ and then for a further $2 \mathrm{~h}$ to $c 20^{\circ} \mathrm{C}$. The containers were removed from the water and the water was examined under ultraviolet light for traces of fluorescein. The results were recorded as a percentage of defective tubes in a batch.

\section{Results}

In this study 18 simple containers from nine manufacturers and four evacuated containers from two manufacturers were evaluated. Tests were also carried out on a specially designed unit (Monovette, Sarstedt), in which the syringe used for blood collection coverts into the container; for the tests on this system the syringes were filled by an adapter to simulate a venepuncture procedure, and they were then subjected to the same protocol as simple containers.

\section{Leakage (Table 1)}

It was decided, arbitrarily, that a blood leakage rate of $1 \%$ or less would be deemed acceptable. By this criterion, 10 of the simple containers, which included the traditional glass bijou bottles and nine types of plastic tube, performed well with blood. The majority of these containers (as well as those which failed the blood leakage test) performed badly in the fluorescein leakage test after the contents had been subjected to a temperature of $-20^{\circ} \mathrm{C}$; however, when the fluorescein test was repeated on containers which had been maintained at room temperature, they performed significantly better. Different leakage rates occur with tubes of different sizes but similar design from the same manufacturer. It might also be noted that some types of tube that passed the fluorescein test were unsatisfactory with blood.

The different procedure for filling evacuated containers with blood in practice required a different test procedure in order to evaluate realistically any leakage from the unopened containers. Using the appropriate test procedures, no tubes were demonstrably defective with regard to leakage of blood or fluorescein although the technique of introducing the material into the container invariably caused slight contamination of the cap.

\section{SPONTANEOUS DISCHARGE}

When the caps of the simple containers were removed by the procedure described above, a relatively large number in each batch displayed spontaneous discharge of their contents (Table 2). The results of testing different types of container are shown in this Table; similar results were obtained with all con-

Table 1 Results of assessment of leakage rate

\begin{tabular}{|c|c|c|c|c|c|}
\hline \multirow[t]{2}{*}{ Manufacturer } & \multicolumn{2}{|l|}{ Description* } & \multirow{2}{*}{$\begin{array}{l}\% \text { Fail rate } \\
\text { by blood leakage }\end{array}$} & \multicolumn{2}{|c|}{$\%$ Tubes leaking on fuorescein test } \\
\hline & Tube & Cap & & $A \dagger$ & $B \ddagger$ \\
\hline \multirow[t]{3}{*}{ Labco } & $5 \mathrm{ml}$ glass (BS 4851) & Plastic screw with liner & $0 \cdot 1$ & 4 & 3 \\
\hline & $\begin{array}{l}10 \text { ml glass (wide mouth) } \\
\text { (BS 4851) }\end{array}$ & Plastic screw with liner & $1 \cdot 0$ & 38 & 17 \\
\hline & $10 \mathrm{ml}$ glass (narrow mouth) & Plastic screw with liner & $3 \cdot 2$ & 2 & 2 \\
\hline \multirow[t]{2}{*}{ Medfor } & $5 \mathrm{ml}$ plastic & Plastic push on & $>10$ & 2 & 0 \\
\hline & $10 \mathrm{ml}$ plastic & Plastic push on & $>10$ & 2 & 0 \\
\hline Nunc & $10 \mathrm{ml}$ plastic & Plastic screw & 0 & 0 & 0 \\
\hline \multirow[t]{2}{*}{ Raven } & $5 \mathrm{ml}$ plastic & Plastic screw & 0.4 & 24 & 0 \\
\hline & $10 \mathrm{ml}$ plastic & Plastic screw & $3 \cdot 3$ & 16 & 13 \\
\hline \multirow[t]{4}{*}{ Searle } & $5 \mathrm{ml}$ plastic & Plastic push on & $2 \cdot 2$ & 72 & 48 \\
\hline & $10 \mathrm{ml}$ plastic & Plastic push on & $3 \cdot 0$ & 80 & 27 \\
\hline & $5 \mathrm{ml}$ plastic & Plastic screw & 0 & 34 & 4 \\
\hline & $5 \mathrm{ml}$ glass & Plastic screw with liner & $1 \cdot 0$ & 46 & $\mathbf{0}$ \\
\hline \multirow[t]{2}{*}{ Seward } & $5 \mathrm{ml}$ plastic & Plastic screw with liner & $1 \cdot 3$ & 2 & $\mathbf{0}$ \\
\hline & $10 \mathrm{ml}$ plastic & Plastic screw with liner & $4 \cdot 1$ & 2 & $\mathbf{0}$ \\
\hline Sterilin & $7 \mathrm{ml}$ plastic & Plastic screw & 0.6 & 16 & 16 \\
\hline \multirow[t]{2}{*}{ Turner Stayne } & $5 \mathrm{ml}$ plastic & Plastic screw & 0 & 16 & $\mathbf{0}$ \\
\hline & $10 \mathrm{ml}$ plastic & Plastic screw & $7 \cdot 0$ & 54 & 47 \\
\hline \multirow{2}{*}{$\begin{array}{l}\text { United Glass } \\
\text { Sarstedt }\end{array}$} & $7 \mathrm{ml}$ glass ('bijou') & Metal screw with rubber liner & $0 \cdot 3$ & 0 & $\mathbf{0}$ \\
\hline & Monovette: $6 \mathrm{ml}$ plastic EDTA & $\begin{array}{l}\text { Plastic screw incorporating } \\
\text { capped syringe }\end{array}$ & $0 \cdot 3$ & 6 & $\mathbf{0}$ \\
\hline \multirow[t]{5}{*}{ Becton Dickinson } & Vacutainer: & & & & \\
\hline & $\begin{array}{l}5 \mathrm{ml} \text { glass EDTA evacuated } \\
10 \mathrm{ml} \text { glass plain evacuated }\end{array}$ & $\begin{array}{l}\text { Rubber closure } \\
\text { Rubber closure }\end{array}$ & Not applicable & $\begin{array}{l}0 \\
0\end{array}$ & $\begin{array}{l}0 \\
0\end{array}$ \\
\hline & Quickdraw: & & & & \\
\hline & $5 \mathrm{ml}$ glass plain evacuated & Rubber closure & Not applicable & $\mathbf{0}$ & $\mathbf{0}$ \\
\hline & $10 \mathrm{ml}$ glass plain evacuated & Rubber closure & & 0 & 0 \\
\hline
\end{tabular}

* Some of these containers may no longer be in production.

†Tubes subjected to temperature range $-20^{\circ} \mathrm{C}$ to $+37^{\circ} \mathrm{C}$.

$\ddagger$ Tubes kept at room temperature throughout. 
Table 2 Examples of spontaneous discharge from various containers

\begin{tabular}{|c|c|c|c|c|c|c|}
\hline \multirow[t]{2}{*}{ Tube/cap } & \multicolumn{3}{|c|}{ Blood } & \multicolumn{3}{|c|}{ Fluorescein } \\
\hline & $a$ & $\boldsymbol{b}$ & $c$ & $a$ & $\boldsymbol{b}$ & $c$ \\
\hline $\begin{array}{l}7 \mathrm{ml} \text { plastic/plastic screw } \\
10 \mathrm{ml} \text { plastic/plastic screw } \\
10 \mathrm{ml} \text { plastic/plastic screw with liner } \\
10 \mathrm{ml} \text { glass narrow mouth/plastic screw with liner } \\
5 \mathrm{ml} \text { plastic/plastic push on } \\
7 \mathrm{ml} \text { glass ('bijou')/metal screw with rubber liner }\end{array}$ & $\begin{array}{r}4 \\
4 \\
2 \\
8 \\
68 \\
8\end{array}$ & $\begin{array}{r}4 \\
4 \\
2 \\
6 \\
44 \\
6\end{array}$ & $\begin{array}{r}32 \\
68 \\
40 \\
18 \\
8 \\
24\end{array}$ & $\begin{array}{r}20 \\
24 \\
10 \\
5 \\
70 \\
30\end{array}$ & $\begin{array}{r}16 \\
20 \\
9 \\
5 \\
38 \\
30\end{array}$ & $\begin{array}{r}52 \\
42 \\
82 \\
78 \\
4 \\
34\end{array}$ \\
\hline
\end{tabular}

$a$ Spray detected with first opening of tubes.

$b$ Spray always detected when tubes opened on three successive occasions.

$c$ No spray detected when opened three times successively.

Results expressed as \% of tubes tested.

tainers tested of each type-in all cases the performance was similar. There was, as a rule, less discharge from tubes containing blood than an aqueous solution of fluorescein. To check whether this was due to the different rheological characteristics and not merely because fluorescein viewed under UV light is a particularly sensitive detector system, the blood tests were performed with blood to which had been added a small amount of fluorescein, and spray droplets on the paper were looked for under both white light and UV light. Identical results were obtained by each, and every 'fluorescent' spot was also identified independently as a 'blood' spot. In a further test of sensitivity of the indicator system a similar blood-fluorescein mixture was used with some containers in the leakage test. There were no significant differences in faults detected under white light and UV light (Table 3). Thus, there appears to be no advantage in adding fluorescein to blood.

The evacuated containers systems were not tested for spontaneous discharge, but there is no reason to believe that they would have performed any better than the simple containers in this test.

Table 3 Comparison of sensitivity of blood and fluorescein as indicators for detecting leakage

\begin{tabular}{llll}
\hline Tube & $\begin{array}{c}\text { Blood alone } \\
\text { (in white light) }\end{array}$ & \multicolumn{2}{l}{ Blood and fuorescein } \\
\cline { 3 - 4 } & & (in UV light) & (in white light) \\
\hline Type A & 2.2 & 2.8 & 2.8 \\
Type B & 3.0 & $1 \cdot 1$ & 1.1 \\
Type C & 0 & 0.8 & 0.8 \\
Type D & 1.0 & 1.0 & 1.0 \\
\hline
\end{tabular}

Results expressed as \% fail rate in blood leakage test.

\section{Comment}

The primary purpose of this study was to develop practical tests for blood specimen container leakage and, at the same time, as a one-off exercise, to try to assess the extent of the problem of leakage. It was not intended as a fully comprehensive survey nor, with the relatively small numbers of containers tested in each batch, was it intended as a quality control procedure. The limitations of the tests that we used are recognised. Thus, the results presented here (whether good or bad) may not necessarily always be reproducible when other batches of the same type of tube are tested. Moreover, it is recognised that manufacturers are frequently modifying their products so that by the time that this report is published a number of the tubes that were tested may no longer be on the market in that precise form.

Minor differences in manufacturing techniques and variability in the primary material seem to influence greatly the integrity of the product. Some manufacturers who are aware of the problem have put in a great deal of work over the last few years in trying to improve the design of the containers and their closure. The main cause of fault appears to be the differences in hardness and in the coefficient of expansion between cap and container, causing loosening of the cap, especially when the container is subjected to temperature variations when the temperature of the container and its contents is lowered to $-20^{\circ} \mathrm{C}$. This means that containers, which may be suitable and satisfactory for blood count specimens, may not be satisfactory when used for specimens of serum, urine, and other body fluids which are usually stored frozen. It seems possible that the problem of leakage, or at least the major source of the problem, might be solved by using liners made from a resilient material such as rubber as a seal. For reasons of economy, manufacturers, having in mind that the item is 'disposable', have, in general, used caps without liners or with nonresilient plastic or cardboard liners. Different designs and the use of more costly materials may well increase the cost to the consumer of the manufactured product. This unpalatable fact should, 
however, be set against the achievement of a higher standard of safety and reliability.

This may also reduce the problem of spontaneous discharge although it is unlikely to overcome it, as this seems to occur equally with plastic and glass containers. As shown by this study, it has not been possible to avoid spontaneous discharge of contents, whether blood or aqueous solution, from a significant proportion of tubes of all types, especially when cap or stopper is removed and replaced two or three times. The fact that the tests for measuring spontaneous discharge are sensitive and that the tubes at present available, or at least those tested, have all failed to meet this criterion should not discredit the test. Rather, the potential hazard of contamination with infected material during this type of manipulation of specimens in the routine laboratory should be recognised; there is need for users to observe safety precautions in their use, and for manufacturers to take serious heed of this problem in their design developments.

\section{References}

British Standards Institution (1972). Medical Specimen Containers for Haematology and Biochemistry: BS 4851.

Cook, I. J. Y. (1972). The collection of specimens and choice of containers with special reference to leakage and aerosol tests. Medical Technologist, 2, No. 12.

International Standards Organisation (1977a). Medical specimen containers up to $25 \mathrm{ml}$ capacity. Second specification working draft (ISO/TC76 N146).

International Standards Organisation (1977b). Evacuated tubes for blood specimen collection. First working draft specification (ISO/TC76 N147).

US National Committee for Clinical Laboratory Standards (1977). Standard for evacuated tubes for specimen collection. Approved Standard: ASH-1.

Requests for reprints to : Dr S. M. Lewis, Department of Haematology, Royal Postgraduate Medical School, Hammersmith Hospital, London W12. 